\title{
PAISAGEM - CONCEITO
}

\section{ÉZLA SOCORRO NEVES}

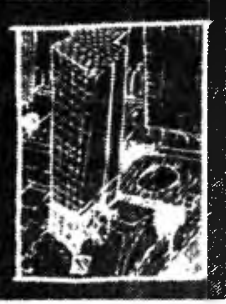

De olhos fechados todos vemos a mesma coisa, ou seja, uma escuridão total. Ao abrirmos os olhos veremos imagens que vão nos sensibilizar e nos farão perceber formas, cores, texturas, luzes, levando à compreensão ou interpretação do "algo" que vemos diferenciadamente, em virtude de nossa personalidade individual, que nos conduz a diferentes formas de percepção. Segundo Rudolf Arnheim ${ }^{1}$, a percepção realiza ao nível sensorial o que no domínio do raciocínio se conhece como entendimento. $O$ ver é compreender e a experiência visual é dinâmica.

A percepção é um fator de extrema importância a considerar para a definição de um conceito sobre paisagem, pois "as paisagens revelam-se diferentemente a cada observador, de acordo com diferentes graus de percepção e interesse" ${ }^{2}$

"O conceito de paisagem envolve o conceito de imagem. Meining (1978) diz que as paisagens se mostram diferentes em função de quem as observa, dada a carga cultural, maneira e freqüência da observação. Qualquer paisagem é composta não apenas pelo que se estende defronte dos olhos, mas pelo que se encontra dentro das mentes, ou seja, somos capazes de ver aquilo que conseguimos interpretar."

Pode-se dizer que a visão da paisagem dependerá do que, como e quando vemos, pois esta visão poderá variar em função de deslocamentos diferentes (visão serial) e em função da luminosidade nos diferentes períodos do dia, sendo portanto uma constante descoberta.

Formada por um conjunto de elementos naturais (produzidos pela natureza) e/ou de elementos artificiais (produzidos pelo homem), a paisagem se apresenta de forma fragmentada a cada observador. A paisagem que vemos deriva de uma dimensão maior e dependendo da escala nem sempre conseguimos visualizar sua totalidade com um olhar.

"Diante de uma paisagem, a nossa vontade de apreendê-la se exerce sobre conjuntos que nos falam à maneira de cartões postais, ou então nosso olhar volta-se para objetos isolados. De um modo ou de outro temos a tendência de 
negligenciar o todo; mesmo os conjuntos que se encontram em nosso campo de visão nada mais são do que frações de um todo.

A idéia do belo, da estética, também está vinculada à percepção. Normalmente buscamos nas paisagens uma beleza ideal, quase sempre associada à idéia do "edén", do "paraíso" introduzida pelo Cristianismo e difundida pela "arte e literatura européias dos sécs. XVII, XVIII e XIX, que invocam imagens romanceadas de uma natureza idealizada" ${ }^{5}$ e pelos artistas plásticos (conhecidos como paisagistas), que "representavam em suas telas o que de mais belo poderia existir numa determinada paisagem"

O valor estético, não é constante, podendo variar de acordo com o padrão cultural de cada sociedade. Um alto valor estético atribuído a uma paisagem num determinado espaço de tempo, poderá ser alterado em outro momento, onde os padrões culturais e os valores estéticos sejam diferentes.

Os conceitos estéticos são muito pessoais, variando de indivíduo para indivíduo, o que pode levar a graus de valorizações atribuídos em função do gosto de cada um.

"O aspecto estético é cultural, está ligado ao nosso mundo particular de valores e conhecimentos." ${ }^{7}$

Os padrões culturais variam com o tempo, que se transforma num fator importante, pois "é através dele que ocorre o dinamismo da paisagem".

"Considerando um ponto determinado no tempo, uma paisagem representa diferentes momentos de desenvolvimento de uma sociedade. A paisagem é o resultado de uma acumulação de tempos."8

Nada em termos de espaço e paisagem pode ser considerado eterno, pois "a paisagem é dinâmica e de evolução constante" ${ }^{\prime 9}$ Todo espaço e toda paisagem são passíveis de modificações ao longo do tempo, variando de acordo com as transformações sociais, econômicas, políticas, culturais, que irão se refletir diretamente nestes elementos, que sempre estarão em busca de uma adaptação às diferentes necessidades da sociedade e suas gerações.

Se observarmos a paisagem de uma cidade de origem muito antiga (uma cidade européia, por exemplo), poderemos verificar as mudanças que esta cidade sofreu ao longo do tempo, os diferentes estilos de arquitetura que ela apresentou de acordo com a época, e que foram se modificando e se acumulando, quando outros modelos ou padrões arquitetônicos foram sendo instituídos. $\mathrm{O}$ mesmo ocorre com paisagens naturais que sofrem diferentes níveis de modificações de acordo com as mudanças da sociedade, ou 
modificando-se por processos naturais, decorrentes do tempo de vida útil dos vegetais que integram esta paisagem, ou ainda por não se adaptarem à influências negativas do ambiente em que se encontram inseridas, como é o caso de poluições ambientais e saturações urbanas.

Ocorre um processo contínuo de alteração do espaço e da paisagem em função das necessidades da sociedade, que em diferentes períodos de tempo poderá utilizá-los de diferentes maneiras renovando, alterando ou até mesmo suprimindo-os, dando origem a novas paisagens.

A qualidade visual de um lugar ou paisagem pode se alterar com o tempo e a sociedade poderá valorizá-los diferentemente. Esta qualidade pode ter um alto valor em determinado período $\mathrm{e}$, em decorrência de alguma alteração no entorno e/ou no tipo de uso, poderá em outro período/momento apresentar esta qualidade reduzida.

Associam-se também à paisagem valores afetivos que serão diferentes para cada indivíduo e estes valores se associam a fatores psicológicos. Cada um de nós sempre guarda na memória a imagem de uma paisagem marcante, que muitas vezes tem um significado afetivo. Sobretudo os indivíduos que se mudaram de uma região para outra, sempre guardam na memória imagens da paisagem de sua região de origem.

Ainda considerando o valor psicológico, podemos dizer, subjetivamente, que através de determinadas paisagens o homem busca o equilibrio.

Dependendo do contexto em que se encontram inseridas, determinadas paisagens, sobretudo as paisagens naturais, proporcionam acesso às imagens visuais que de certo modo transmitem sensações de tranqüilidade e paz ao homem, que se associam à idéia de equilíbrio. São imagens visuais que, normalmente, acalmam o olhar, num confronto com o caos visual dominante nos centros urbanos, onde a confusão de placas, cores, símbolos, formas e a agitação da vida cotidiana em conjunto transmitem sensações contrárias àquelas associadas à idéia de equilíbrio.

"Compreende-se que o homem procura o equilibrio em todas as fases de sua existência física e mental. O equilíbrio continua sendo a meta final de qualquer desejo a ser realizado, de qualquer trabalho a ser completado, qualquer problema a ser solucionado. $O$ equilibrio que se consegue na aparência visual é desfrutado pelo homem como uma imagem de suas aspirações mais amplas"10 
Talvez esta busca constante explique a idéia que se tem da natureza equilibrada.

Hoje uma nova corrente científica afirma que "a natureza está num constante estado de transformação e flutuação. Mais do que constância e equilibrio a regra é a mudança e a agitação. E que, ao invés de se insistir que os homens não devem alterar um 'suposto' equilíbrio da natureza, se deveria escolher qual condição natural promover. $\mathbf{E}$ que, algum tipo de equilibrio pode existir em certas escalas de tempo e espaço, mas não para sempre"11 $\mathrm{Em}$ função disto, o homem precisa mudar a visão que tem da natureza e a idéia de que ela tem que ser mantida intocada para continuar no seu equilíbrio constante, que como já vimos não acontece a nível concreto.

A história da humanidade sempre esteve associada à da natureza, afinal o homem faz parte dela. "As atitudes do homem para com a natureza/paisagem tem variado no tempo distinguindo-se três fases: a) A natureza como sinônimo de Deus, quando devido ao desconhecimento, era temida pelo homem; b) A natureza encarada como meio. $O$ homem aceita os condicionantes naturais como fatores limitantes, aprende então a usá-la; c) Os avanços tecnológicos conquistados pela sociedade não se intimidam frente aos fatores condicionantes ou limitantes da natureza. $O$ homem consegue superar, transformar ou minimizar fatores limitantes da natureza." ${ }^{12}$

"A paisagem pode ser considerada como um reflexo direto do dinamismo da natureza e dos seus sistemas sociais, que se altera constantemente de acordo com o tempo e o momento social. ${ }^{13}$

"Estas alterações introduzidas pelo homem no ambiente são sempre procedidas de forma rápida e variada, não permitindo muitas vezes que haja a recuperação normal da natureza. ${ }^{14}$

"Todos nós temos bastante experiência de contínuas transformações: desde que o homem apareceu sobre a terra as transformações da Natureza se acresceram àquelas produzidas pelas atividades do homem. Há já um século e especialmente nas últimas décadas, as transformações foram tão rápidas, e também tão extensas que se tornou extremamente difícil segui-las e compreendê-las." ${ }^{15}$

Ao considerar a paisagem, que faz parte da natureza, não podemos deixar de considerar seus componentes principais que são: "Biótico, compreendendo o conjunto dos componentes vegetais e animais; Abiótico, agrupando todos os elementos abióticos (solo e clima) e Intervenção Antrópica, interferindo nos dois primeiros" ${ }^{16}$ 
Sendo a paisagem "o suporte físico no qual se estrutura a sociedade, englobando desde espaços primitivos, sem presença humana, a diferentes tipos de espaços ou regiões, apropriados de diferentes maneiras pelo homem". Temos então a paisagem como um resultado de processos naturais decorrentes da constante transformação da natureza interagindo com os processos sociais, produzidos pelo homem de modo muito mais acelerado do que os processos evolutivos naturais.

Retirando da natureza os recursos materiais, visando assegurar sua sobrevivência, o homem desenvolveu meios de exploração, criando artifícios capazes de aumentar sua ação dominadora e transformadora da natureza. Colocando-se como centro principal, as mudanças sempre aconteceram em função do homem que buscou adequar a natureza as suas necessidades e com isto foi capaz de promover transformações violentas no meio em que vive, algumas vezes irrecuperáveis.

Como uma decorrência do esgotamento destes recursos, surge uma preocupação generalizada pela natureza em todos os níveis e em todas as regiões do mundo e, hoje, palavras como ecologia, preservação, conservação, meio-ambiente, passaram a integrar o vocabulário de todos, sobretudo daqueles interessados pelos problemas relativos à natureza.

Temos que deixar de "tratar a paisagem como uma sucessão de cenas 'bonitas' onde se desenrolam alguns momentos da vida humana no meio de árvores, flores e fontes, mas sim como um conjunto de espaços onde se desenvolve o cotidiano da vida das populações" ${ }^{17}$

Para se trabalhar com as paisagens deve-se cultivar o modo de vê-las, que deverá tentar ser o mais realista possível, considerando as potencialidades do suporte físico e seu ecossistema, suas características morfológicas, sua dinâmica, dimensão/escala, identidade, seu valor turístico, potencialidades paisagísticas e ambientais, suas diversidades e homogeneidades, sua evolução natural, suas possíveis funções, investigando as relações entre este suporte ecológico/ambiental, que inclui o conjunto de elementos geográficos e, as intervenções humanas, que inclui o conjunto de elementos artificiais, levando em conta fatores como o tempo, a percepção, o sentido, os fatores psicológicos, com o objetivo final de buscar uma melhor qualidade de vida para o homem, evitando a produção de paisagens desinteressantes, monótonas ou de difícil compreensão e tentar suprir a necessidade que o homem tem destas paisagens. 


\section{NOTAS}

(1) ARNHEIM, Rudolf. Arte Percepção Visual: uma Psicologia da Visão Criadora. São Paulo. Pioneira. EDUSP, 1986.

(2) LEITE, Maria Angela Faggin Pereira. Uma fundamentaçāo geográfica ao Paisagismo Regional. Paisagem e Ambiente. Ensaios III. FAUUSP, São Paulo, 1989.

(3) PELlegrino, Paulo Renato Mesquita. A Paisagem Possivel. Paisagem e Ambiente. Ensaios III. FAUUSP, São Paulo, 1989.

(5) MACEDO, Silvio Soares; PELLEGRINO, Paulo Renato Mesquita. Ética e Estética: o destino do litoral. Paisagem e Ambiente. Ensaios III. FAUUSP, São Paulo, 1989.

(6) DEGREAS, Helena Napoleon. Paisagem e Proteção Ambiental: do Conceito ao Desenho. São Paulo, 1991. Diss. (Mestr.) - FAUUSP.

(7) ABBUD, Benedito. A Vegetação nos Projetos de Paisagismo. São Paulo. Diss. (Mestr.) - FAUUSP.

(8) SANTOS, Milton. Da Sociedade à Paisagem: o Significado do Espaço Humano. s.n.t. (Apostila do Curso de Especialização: Patrimônio Ambiental Urbano. FAUUSP, 1978).

(9) Idem nota 2.

(10) Idem nota 1.

(11) STEVENS, Willian K. Uma nova visão da natureza. Jomal da Tarde, São Paulo, 01 set. 1990.

(12) Idem nota 6.

(13) LAURIE, Michael. Introducción a la Arquitectura del Paisaje. Barcelona, Gustavo Gilli, 1983.

(14) MOTA, Suetônio. Planejamento Urbano e Preservação Ambiental. Fortaleza. UFC., 1981.

(15) MAGNOLI, Miranda M. E. M. Território. s.n.t. (Apostila de aula. Curso de Especialização de Paisagismo. FAUUSP, São Paulo, 02/07/1981.)

(16) Idem nota 6.

(17) MAGNOLI, Miranda M. E. M. Programa e Plano de Ensino. Documento de aula. fev. 1984. 